Published in final edited form as:

Biochim Biophys Acta. 2014 May ; 1841(5): 773-782. doi:10.1016/j.bbalip.2013.09.007.

\title{
Sphingolipids in colon cancer
}

Mónica García-Barros,

Health Science Center, Stony Brook University, 100 Nicolls Road, T15, 023, 11794, Stony Brook, NY, USA, Monica.Garcia-Barros@stonybrookmedicine.edu

\section{Nicolas Coant,}

Health Science Center, Stony Brook University, 100 Nicolls Road, T15, 023, 11794, Stony Brook, NY, USA, Nicolas.Coant@stonybrookmedicine.edu

Jean-Philip Truman,

Health Science Center, Stony Brook University, 100 Nicolls Road, T15, 023, 11794, Stony Brook, NY, USA, Jean-Philip.Truman@stonybrookmedicine.edu

Ashley J. Snider, and

VAMC Northport, 79 Middleville Road, Northport, NY, USA, Health Science Center, Stony Brook University, 100 Nicolls Road, T15, 023, 11794, Stony Brook, NY, USA,

Ashley.Snider@stonybrookmedicine.edu

\section{Yusuf A. Hannun}

Health Science Center, Stony Brook University, 100 Nicolls Road, L4, 178, 11794, Stony Brook, NY, USA, Yusuf.Hannun@stonybrookmedicine.edu, Phone 1631-444-8067

\begin{abstract}
Colorectal cancer is one of the major causes of death in the western world. Despite increasing knowledge of the molecular signaling pathways implicated in colon cancer, therapeutic outcomes are still only moderately successful. Sphingolipids, a family of $\mathrm{N}$-acyl linked lipids, have not only structural functions but are also implicated in important biological functions. Ceramide, sphingosine and sphingosine-1-phosphate are the most important bioactive lipids, and they regulate several key cellular functions. Accumulating evidence suggests that many cancers present alterations in sphingolipids and their metabolizing enzymes. The aim of this review is to discuss the emerging roles of sphingolipids, both endogenous and dietary, in colon cancer and the interaction of sphingolipids with WNT/ $\beta$-catenin pathway, one of the most important signaling cascades that regulate development and homeostasis in intestine
\end{abstract}

\section{Keywords}

Colorectal cancer; Sphingolipids; Dietary; Ceramide; Sphingosine; Sphingosine-1-Phosphate

(C) 2013 Elsevier B.V. All rights reserved.

Correspondence to: Yusuf A. Hannun.

Publisher's Disclaimer: This is a PDF file of an unedited manuscript that has been accepted for publication. As a service to our customers we are providing this early version of the manuscript. The manuscript will undergo copyediting, typesetting, and review of the resulting proof before it is published in its final citable form. Please note that during the production process errors may be discovered which could affect the content, and all legal disclaimers that apply to the journal pertain. 


\section{Introduction}

Colorectal cancer (CRC) is the third most commonly diagnosed cancer in western countries. The most recent data published by the World Health Organization reported an incidence of 25.0 per 100,000 women and 34.1 per 100,000 men in the USA for the year 2008. They reported, for the same year, 7.7 deaths per 100,000 women and 9.9 per 100,000 men [1]. Estimates made by the American Cancer Society for the year 2013 predicted 142,820 new cases and 50,830 deaths for both sexes [2]. Age remains a fundamental risk factor but modifiable factors such as obesity, physical inactivity, a diet high in red or processed meat, alcohol consumption, long-term smoking, and possibly very low intake of fruits and vegetables may also play an important role in colon cancer incidence. Despite the fact that sporadic colon cancer is the most common diagnosis, heredity can also be an important factor involved in colon cancer occurrence [3]. The very well described familial adenomatous polyposis (FAP) and its attenuated form (AFAP) are due to mutations in the adenomatous polyposis coli (APC) gene [4, 5]. Studies have also reported an association of colon cancer with specific hereditary syndrome such as Lynch Syndrome or MUTYH biallelic mutation [6-8]. Moreover, familial history of colon cancer, independently of any identifiable syndrome, is also an increased risk factor for CRC [9].

The intestinal epithelium is regenerated throughout life with intense proliferation occurring in the crypts of Lieberkühn, which contain stem cells and their progeny [10]. The progeny or transit-amplifying cells divide 4-5 times in the crypt before they migrate and differentiate completely into specialized intestinal epithelial cell types. The homeostasis of intestinal epithelium is based on a tight regulatory balance between self-renewal at the bottom of the crypt and differentiation [11]. It is disruption of this tightly regulated balance, through a series of known mutations that leads to intestinal tumorigenesis. Sporadic CRC is one of the best studied malignancies and the various stages of the disease have been well defined [12]. It is believed that CRC occurs as a result of the activation of oncogenes coupled with the inactivation of tumor suppressor genes. Mutations in several genes are required (WNT/ $\beta$ catenin pathway, K-Ras, Smad4, p53) and although these genetic alterations occur in a preferred sequence, the accumulation of changes determines the tumor properties [11]. Aberrant crypt foci (ACF) is the smallest identifiable lesion and is considered the putative premalignant lesion for colon cancer [13]. ACF may present different histologic features ranging from hyperplasia to dysplasia, and their involvement in CRC is not totally understood. The most common ACF is associated with hyperplastic crypts, and generally presents mutations in K-Ras although it rarely develops malignant carcinoma. However, the dysplastic ACF presents mutations in APC and is frequently associated with CRC [14]. Adenomas progress into carcinomas and malignancy coincides with inactivation of the p53 gene in 50\% of the tumors. In general it is believed that CRC evolves through a series of restriction points, at which only those cells acquiring the correct mutational advantages can expand.

Sphingolipids constitute a family of lipids that are evolutionarily conserved among all eukaryotes. For many years, these molecules were considered structural components of biologic membranes, however studies over more than two decades have disclosed important biologic activities of many sphingolipids. Sphingolipids such as sphingosine (SPH), ceramide, sphingosine-1-phosphate (S1P) have been implicated as modulators of physiologic and pathophysiologic processes such as cell growth, cell death, autophagy, angiogenesis, cell adhesion, differentiation, migration, senescence, intracellular trafficking, stress [15-17] and inflammatory responses [18]. Ceramide and S1P often exert opposing functions in the cell; as ceramide has been shown to mediate cell cycle arrest and cell death in response to cell stress $[19,20], \mathrm{S} 1 \mathrm{P}$ has been shown to promote cell survival and proliferation [21]. The flux between these various metabolites is tightly controlled through 
several enzymes which are critical in regulating the levels and function of these bioactive sphingolipids.

Alterations in bioactive sphingolipids and their metabolism have been linked to several human diseases including cancer [22-24]. Accumulating evidence also suggests that alterations of the sphingolipid pathway, both by addition of dietary sphingolipids or modification of endogenous enzymatic activity, may play a role in colon cancer development which will be the subject of discussion in this review.

\section{Part I: Sphingolipids, a class of bioactive lipids}

Briefly, ceramide is considered the central hub of sphingolipid metabolism. The de novo pathway of ceramide synthesis starts with the condensation of serine and palmitoyl-CoA catalyzed by serine palmitoyl transferase to generate 3-keto-dihydrosphingosine [25]. 3keto-dihydrosphingosine is reduced to form dyhydrosphingosine (sphinganine), that is then $\mathrm{N}$-acylated by (dihydro)ceramide synthases (CerS) to produce dihydroceramide by the action of one of six (dihydro)ceramide synthases [26]. Ceramide is then generated as the product of dihydroceramide desaturase. Ceramide can be converted to sphingomyelin (SM) by sphingomyelin synthase, and SM can be hydrolyzed into ceramide by the activity of several different sphingomyelinases (SMase) characterized by the $\mathrm{pH}$ required for optimal enzymatic activity [27-29]. Ceramide can also be glycosylated by glucosylceramide synthase (GCS) to generate glucosylceramide [30]. In addition, ceramide can be further hydrolyzed to produce SPH through the action of several different ceramidases (CDase), also characterized by the $\mathrm{pH}$ required for optimal activity. SPH can in turn be phosphorylated by sphingosine kinases 1 and 2 (SK1 and 2) to form S1P or reacylated back to ceramide [31]. S1P can be metabolized back to SPH by S1P phosphatases, whereas S1P lyase (SPL) irreversibly cleaves S1P to generate ethanolamine phosphate and hexadecenal resulting in the only exit pathway from metabolism $[32,33]$.

Alterations in bioactive sphingolipids and their enzymes have been linked to several different pathologies including: Faber disease [lack of acid CDase (aCDase) activity], Fabry disease [deficiency in alpha-galactosidase A (GLA)], Niemann-Pick disease [lack of acid SMase (aSMase) activity], Gaucher disease (lack of $\beta$-glucosidase), Tay-Sachs disease, Sanhoff disease and GM2A deficiency (accumulation of GM2 gangliosides), (reviewed in [34]). Other diseases such as Alzheimer's [35], atherosclerosis [36], cystic fibrosis [37] and cancer have also been linked to alterations of sphingoipids. In addition, sphingoipids have been associated with cancer progression and response to cancer treatment, including resistance to chemotherapeutic drugs. Indeed, several cancer models have shown significant alterations in enzymes implicated in ceramide generation [aSMase, neutral SMase (nSMAse), CerS] and degradation [aCDase and neutral CDase (nCDase)], resulting in loss of ceramide [38]. In addition, high levels of S1P have been detected in several cancers as a result of alteration of enzymes implicated in its phosphorylation and catabolism [39]. Although this review is focused on the role of sphingoipids in colon cancer, it is important to note that sphingoipids may also play a significant role in other cancers including prostate cancer, breast cancer and head and neck cancer (reviewed in [24]).

\subsection{Metabolism of sphingoipids in the colon}

Sphingoipids are enriched in the apical membrane of the polarized cells found throughout the intestinal tract. They are considered essential for structural integrity, and it is believed they may act as receptors for toxins, viruses, and bacteria [40]. In particular, the small intestine is characterized by an unusually high content of sphingolipids, comprising $40 \%$ of the lipids localized in the apical membrane [41]. The metabolism of dietary SM begins with the release of cholecystokinin from endocrine cells in the intestine, which then stimulates 
the release of alkaline SMase (alk-SMase) from the gallbladder as well as the secretion of trypsin from the pancreas. This trypsin cleaves the alk-SMase bound in the intestinal mucosa to be released into the lumen for enhanced enzymatic activity [42]. Alk-SMase hydrolyzes $\mathrm{SM}$ into ceramide within the intestinal lumen, and this ceramide is further hydrolyzed by the membrane bound nCDase to form SPH. SPH is absorbed inside the enterocytes by a diffusion mechanism and can be phosphorylated and converted to S1P by the action of SK1 and SK2. Inside the enterocytes, S1P, as mentioned above, can be degraded by SPL or synthesized back to ceramide and other complex sphingolipids [32].

1.1.1 Alkaline SMase-In several studies, alk-SMase has been implicated in the development of colon cancer [43, 44]. In normal tissue, a gradient in the expression and activity of alk-SMase from the ascending colon to the rectum has been shown, while in CRC this activity is decreased by $75 \%$ with almost undetectable levels in adenoarcinomas [45]. Measurement of alk-SMase activity in CRC patients revealed that the decreased activity in adenomas is not directly linked to mutations in the APC gene [43]. Interestingly this was also observed in patients with chronic colitis [46]. The expression of alk-SMase has been reported to be changed in response to dietary factors and also in response to two chemical agents. The first, ursodeoxycholic acid (UDCA, present in bile), increased the activity of alk-SMase in intestinal mucosa and inhibited the development of colon carcinoma [47]. This finding has been confirmed in vitro in HT29 cells, where treatment with UDCA increased alk-SMase activity which was associated with a decrease in cell proliferation and caspase activation [48, 49]. The second factor associated with increasing alk-SMase activity is 5aminosalicylic acid, an anti-inflammatory drug that has been shown to increase alk-SMase levels in the colonic mucosa after ingestion [50]. Both agents have also shown chemopreventive effects against colon cancer [50, 51]. The decrease of alk-SMase activity detected in colon cancer reduces the hydrolysis of SM and therefore reduces ceramide generation [52]. Since ceramide can inhibit proliferative and anti-apoptotic pathways and also activate anti-proliferative and apoptotic pathways, lack of ceramide in colon cancer may contribute to colon cancer development.

1.1.2. Sphingosine kinase-As discussed above, SK1 and 2 can phosphorylate SPH to form S1P, which exerts proliferative effects in colon cancer cells. Expression of SK1 and 2 have been shown in both the small intestine and in the colon [53]. SK1 has been shown to be over-expressed in human colon cancer compared to normal colon mucosa [54]. In particular, adenomas have higher expression of SK1 when compared to normal mucosa, and metastatic colon cancer has higher SK1 expression than non-metastatic cancer [39]. Kohno et al showed that SK1 expression was required for small intestinal tumor cell proliferation in $\mathrm{APC}^{\mathrm{Min} /+}$, mouse model for intestinal neoplasia, since deletion of the SK1 gene in these mice suppressed adenoma size but not their incidence. This study also demonstrated that epithelial cell proliferation in the polyps was significantly attenuated suggesting that SK1 may regulate adenoma progression [55]. Interestingly, deletion of S1P receptors 2 and 3, and the loss of an allele in receptor 1 did not recapitulate the SK1 deletion. Moreover, while tissue SPH content was elevated in the adenomas of $\mathrm{APC}^{\text {Min/+ }} \mathrm{SK} 1^{-/-}$as expected, S1P levels were not significantly altered. In another colon cancer murine model of colitis associated cancer induced with azoxymethane (AOM) and dextran sulfate sodium (DSS), SK1 and S1P were significantly elevated in colon cancer tissues compared to normal mucosa [39]. Additionally, SK1 ${ }^{-/-}$mice subjected to AOM/DSS treatment presented not only significantly fewer ACF but also a reduction in colon cancer development [39]. Interestingly, SK2 ${ }^{-/-}$mice have been shown to develop tumors similar to WT mice upon administration of AOM/DSS [56]. These results suggest that decreased SK1, but not SK2 activity, decreases both proliferation and colon cancer formation, further suggesting a 
pivotal role for bioactive sphingolipids (possibly a combination of effects of S1P and ceramide) in CRC.

1.1.3. S-1-P Lyase (SPL) and S-1-P phosphatase-The levels of S1P in the colon are not only controlled by SKs, but also by enzymes that control its metabolism, and these include SPL and S1P phosphatase. S1P can be metabolized back to SPH by S1P phosphatases or by type 2 phosphatidate phosphohydrolases. In addition, S1P can also be degraded in an irreversible manner by SPL. In the apex of the intestinal villi, there is a strong catabolism of S1P due to high expression of SPL. As proliferation in the intestinal epithelium occurs at the bottom of the crypt, controlling the levels of S1P by SPL at the top of the crypt may be a mechanism to prevent mitogenic signaling and promote the rapid cell turnover characteristic of this tissue [10]. It is important to note that S1P has been also implicated in live cell extrusion in colon epithelium, which has been suggested to be a tumor-supressive mechanism that prevents the accumulation of excess epithelial cells and maintains homeostatic cell number by matching the number of dividing cells with the number of dying cells [57]. APC ${ }^{\text {Min/+ }}$ mice have not only high levels of SPH and S1P in general, but also show decreased expression and activity of SPL in adenomas when compared to intestinal epithelium [58]. In colon cancer patients, the expression of SPL (and also S1P phosphatase) has been shown to be downregulated, indicating that breakdown of S1P may be blocked in colon cancer [59].

1.1.4. Neutral ceramidase-nCDase is a key enzyme in regulating the balance between ceramides, SPH and S1P. In the intestine this enzyme is expressed in the plasma membrane of intestinal epithelial cells, and includes a transmembrane domain and an extracellular catalytic domain [60]. Intestinal nCDase was initially purified in rat intestine mucosa [61] and in human gastrointestinal tract through the analysis of ileostomy contents [62]. Like alkSMase, nCDase distribution is higher in the small intestine, peaking at the jejunum, and decreasing in the colon $[63,64]$. CDase $^{-/-}$mice are viable and do not present any severe pathology [65]. While in general sphingolipids levels were similar to those in control mice, the levels of C16:0 ceramide were significantly increased in the intestinal tract. Also, after feeding the $\mathrm{nCDase}^{-/-}$animals a diet supplemented with $0.1 \%$ milk SM, the amount of ceramide in feces was much higher than in the control mice, suggesting defective intestinal digestion of dietary sphingolipids [65]. The role of nCDase in the development of colon cancer has yet to be elucidated.

1.1.5. Glucosylceramide synthase_GCS catalyzes the formation of glycosphingolipids. There is evidence suggesting that conversion of ceramide into glycosphingolipids is related to cancer invasiveness, metastasis and drug resistance. Ceramide glycosylation, through GCS, allows cellular escape from ceramide-induced programed cell death in cancer cell lines [66]. It is been shown that glucosylceramide accumulates in adriamycin-resistant breast carcinoma cells, in vinblastine-resistant epithelioid carcinoma cells, and in tumor specimens from patients showing poor response to chemotherapy [67]. This multidrug resistance can be increased by overexpression of GCS, and also can be reversed in human cancer breast cells by GSC gene targeting with siRNA [68]. In vitro, colon cancer cells resistant to drug treatment exhibited high levels of expression of GCS [69], while inhibition of this enzyme resulted in enhanced apoptosis [70].

Altogether, these studies suggest that alterations in the metabolism of sphingolipids may play a critical role in susceptibility to colon cancer. Several studies suggest an association between colon carcinoma and changes in sphingolipids enzymes as shown in Figure 1. These alterations in enzyme expression and activity suggest that colon cancer may be associated with decreased ceramide and increased S1P levels. 


\section{Part II. Dietary sphingolipids in colon cancer}

Sphingolipids form a natural part of a normal diet, although there is no known nutritional requirement for them [71]. Even though most of the sphingolipids that enter the gastrointestinal system are hydrolyzed in the small intestine, a small percentage also enters the large intestine. The effect of dietary sphingolipids in colon cancer has been actively studied both in vitro and in vivo. Evidence of the importance of dietary sphingolipids in CRC was first described by Dudeja $e t$ al. [72], where they found differences in both sphingolipid composition and sphingolipid enzyme activities between tumor and normal tissue. In particular, their data demonstrated that mice treated with the pro-carcinogen 1.2Dimethylhydrazine (DMH) displayed an increase in SM levels in colonic tissues even before the appearance of adenomas, and this was accompanied by a reduction of SMase. DMH treatment also decreased glyco-sphingolipids and induced changes in the glyco-sphingolipid pattern [73]. These early discoveries, together with evidence suggesting that high-fat diet increases the risk of colon cancer, provided a basis to investigate the effect of dietary sphingolipid in colon cancer.

\subsection{Effects of sphingolipids in colon cancer cells}

Sphingoid bases and ceramide have been shown to induce apoptosis in colon cancer cells and suggested as potential mediators of the protective role of more complex dietary sphingolipids in CRC development [74]. Also, the interplay between ceramides of various chain lengths seems to be crucial for cancer progression. Ceramide production and its biological function are highly dependent on the length of the covalently linked fatty acid controlled by the six isoforms of mammalian CerS ( 1 to 6 ). They differ in their tissue expression pattern and in their substrate specificity resulting in the production of ceramides with different $\mathrm{N}$-acyl side chains. For example, cyclooxygenase-2 (COX-2) inhibitor (celecoxib) mediates its antiproliferative effects, in part, by selectively activating CerS6 in human colon carcinoma in HCT116 cells, generating an increase of C16:0 ceramide. Overexpressing CerS 2, 4 or 6 in colon and breast cancer cells demonstrated that overexpression of either CerS4 or 6 increased generation of long chain C16:0, C18:0 and C20:0-ceramides, yet the overexpression of CerS2 had no effect on ceramide production. The upregulation of CerS4 or 6 led to the inhibition of cell proliferation and induction of apoptosis, while upregulation of CerS2 increased cell proliferation [75].

It is important to remark that colon cancer cells present differential expression of certain proteins in response to ceramide. In particular, HCT116 cells treated with C6-ceramide showed 43 proteins differentially expressed compared to untreated cells, and many of these proteins are implicated in different cellular process such as apoptosis (caspase-8, caspase-10) and growth arrest (PCNA) [76].

Thus altered sphingolipid composition has been shown in colon cancer cells [77, 78]. Specific sphingolipids (and bioactive sphingolipid metabolites) together with changes in the expression and/or function of sphingolipid-metabolizing enzymes, could impact therapeutic response. Here we will review the effects of exogenous sphingolipids in colon cancer cells, effect of specific targeting of sphingolipid metabolism and alteration of sphingolipid metabolism by chemotherapeutic drugs (Figure 2).

2.1.1 Effects of adding exogenous sphingolipids-Cell death, via activation of caspase-3 and cytochrome c release in SW403 cells has been demonstrated to occur upon treatment with two short-chain ceramide analogues (C2 and C6-ceramide) and two inhibitors of CDases (D-MAPP and B13). Also, the cytotoxic effects of C6-ceramide in colon cancer cells (LoVo, HT29 and HCT15) can be magnified when combined with different Pglycoprotein antagonists such as tamoxifen, cyclosporine A, VX-170 and verapamil (that 
inhibit conversion of ceramide to glucosylceramide) with an increase in caspase activation, PARP cleavage, DNA fragmentation, cell cycle arrest, increased mitochondrial membrane permeability and enhanced expression of p53 [79]. In another study, SPH, sphinganine and $\mathrm{C} 2$-ceramide [74], but not $\mathrm{C} 2$-dihydroceramide, inhibited growth and caused death in colon cancer cells (HT29 and HCT-116) in a time and dose-dependent manner. In addition, C2ceramide also induced apoptosis and cell cycle arrest at the G2/M phase causing an accumulation of cells in the $\mathrm{S}$ phase [74]. The 4,5-trans double bond of ceramide was necessary for the apoptotic effects of $\mathrm{C} 2$-ceramide, but not for the sphingoid bases [80]. C2ceramide has been implicated in apoptosis and cell cycle arrest, as well as in mediating macroautophagy by increasing proteolysis and accumulation of autophagic vacuoles in HT29 cells. In this case ceramide reversed the interleukin 13-dependent inhibition of macroautophagy by interfering with the activation of Akt and stimulating the expression of the autophagy gene product beclin-1, implicating ceramide for the first time in control of a major lysosomal pathway [81]. Of particular interest is that SPH and its methylated derivative N,N-dimethylsphingosine (DMS), a non-specific SK inhibitor, induced apoptosis specifically in colon cancer cells (HT29, HRT18, MNK74 and COLO205) but not in primary cultures [HUVEC (human umbilical vein endothelial cells) or mesangial cells] [82]. Treatment of SW403 with a cationic long chain ceramide [ $\omega$-pyridinium bromide D-erythroC16-ceramide (LCL-30)], targeting negatively charged mitochondria, induced cell death with mitochondrial accumulation and subsequent release of cytochrome $\mathrm{c}$ and activation of caspase-3 and caspase-9 [83]. Sphingoid bases prepared from plants also decreased cell viability in SW403 in a dose-dependent manner, similar to that of cells treated with SPH, and its effects were, at least in part, mediated by activation of caspase-3 [84].

In cancer cells, including colon cancer cells, S1P has been shown to stimulate proliferation by activating p38 and ERK MAP kinases [85]. In particular, S1P activated invasion, proliferation and protection from cytotoxic agents in HT29 and interestingly, addition of anti-S1P monoclonal antibody reversed all these processes by increasing activation of caspase-3 [85]. These results, together with the effect of S1P antibodies reducing tumor progression in murine xenografts and allografts, suggest the bioactive lipid S1P as a target for cancer therapy [86].

SM metabolism seems to play an important role in response to therapy, as some chemotherapeutic drugs (daunorubicin), $\mathrm{H}_{2} \mathrm{O}_{2}$, heat, and ionizing radiation induce formation of ceramide from SM hydrolysis as well as from activation of the de novo and salvage pathways. The resulting ceramide has been shown to be responsible for initiating the apoptotic response. Exogenous administration of SM to colon cancer cells (HCT15 and MOSER) increased 5- fluorouracil (5-FU) and doxorubicin sensitivity by 100-300\%, however this effect was not achieved in other colon cancer cell lines such as HT29, Lovo and WiDr, nor in HUVEC [87], suggesting that these different responses to co-treatment with SM may be due to alterations in SM/ceramide metabolism in the non-responsive cells. To study this possibility, HT29 cells cultured with gradually increasing concentrations of colchicine (an antimitotic agent) not only displayed an increased resistance to colchicine, doxorubicine, etoposide, vincristine and taxol, but also showed higher levels of glucosylceramide and galactosylceramide, confirming that specific changes in sphingolipid levels could be associated with different responses to therapeutic agents [88].

TRAIL (TNF-Related Apoptosis-Inducing Ligand) is a member of the tumor necrosis factor superfamily that selectively induces apoptosis in malignant cells, although not all cancer cells are susceptible [89]. Resistance to TRAIL has been associated with defects in ceramide signaling in colon cancer cells. To investigate whether TRAIL resistance was due to low ceramide levels or defects in sphingolipid metabolism, two colon cancer cells (SW480 and SW620) from the same patient (primary and subsequent metastasis respectively) with 
different sensitivity to this pathway were analyzed. While the overall levels of ceramide were comparable in both cell lines, SW480 cells, which respond to TRAIL, contained a higher percentage of C16 and C18-ceramide and lower C24-ceramide than the TRAILresistant SW620 cells. Upon TRAIL treatment mainly C16-ceramide was increased in SW480 cells but not SW620, parallel with caspase-3/7 activation. Interestingly, combination of C6-ceramide with TRAIL resulted in apoptosis in SW620 cells. These results suggest that ceramide plays a role in promoting TRAIL-mediated apoptosis and that TRAIL-resistant cancers may benefit from combination therapy with ceramide or agents that enhance ceramide accumulation [90]. Later studies identified CerS6, which preferentially generates C16-ceramide, as a protein able to influence susceptibility to TRAIL [91].

\subsubsection{Specific targeting of sphingolipid metabolism and its effect on colon} cancer cells-Modification of sphingolipids affects metabolism and apoptosis in colon cancer cells. The CDase inhibitor B13 proved to be specific for colon cancer cells since normal liver cells were resistant to treatment with no increase of ceramide or apoptosis [92]. The effect of increased ceramide levels in HT29rev cells by either incubating the cells with bacterial SMase (bSMase) or adding C2-ceramide was evaluated by Veldman et al. [93]. Treatment with $\mathrm{C} 2$-ceramide resulted in rapid accumulation of the compound by the cells and in induction of apoptosis, whereas bSMase treatment did not induce apoptosis despite hydrolyzing cellular SM and increasing ceramide levels. The bSMase-generated ceramide, however, was converted to more complex sphingolipids. Even after the use of inhibitors to block this conversion into more complex lipids, thereby inducing an accumulation of ceramide in the cell, apoptosis was not detected. These results suggested that $\mathrm{C} 2$-ceramide is able to reach putative intracellular targets involved in the propagation of the apoptotic signal, but not ceramide generated by aSMase [93]. Ceramide generated by the addition of exogenous aSMase contributes to tumor necrosis factor alpha (TNFa) mediated apoptosis in HT29 [94]. In a complementary study TNFa induced apoptosis in a time and dosedependent manner, but downregulation of aSMase prevented TNF-stimulated apoptosis [95]. In addition, the relationship between SK, cellular ceramide concentration, and chemosensitivity was investigated in nine colon cancer cell lines. SK1 and SK2 activity and protein expression were the highest in RKO cells and the lowest in HCT116 [96]. HCT116 were sensitive to the effects of oxaliplatin, while RKO were the most resistant. Treatment of HCT116 with oxaliplatin increased C16, C24 and C24:1-ceramides, but not in RKO. Pretreatment of HCT116 with an inhibitor of nSMase suppressed the increase in ceramide levels and activation of caspases, suggesting that ceramide formation was due to the activation of nSMase, instead of aSMase. In contrast, treatment of RKO with SK1 and SK2 siRNA suppressed cell viability, increased caspase activity and cellular ceramide formation upon oxaliplatin treatment. Another pathway demonstrated to be affected by SK1 and SK2 silencing is the AKT pathway, decreasing its phosphorylation and increasing p53 and p21 protein levels in response to oxaliplatin. These studies indicated that SK and nSMase contribute to the regulation of chemosensitivity controlling ceramide formation and affecting the AKT pathway [96].

\subsubsection{Alteration of sphingolipid metabolism by chemotherapeutic drugs-}

CerS6 is a key enzyme implicated in the response to chemotherapy. Treatment of HCT116 cells with celecoxib, which induces apoptosis and inhibits proliferation in cancer cells, led to a significant increase in the levels of C16-ceramide, with a concomitant increase of CerS6 activity [97]. siRNA against CerS6 showed that this enzyme was responsible for the increase of C16:0-ceramide and also partially protected the cells from the cytotoxic effects of celecoxib [97]. These results were confirmed in vivo using HCT-116 xenografts. In another study, HT29 treated with the topoisomerase I inhibitor camptothecin (first line treatment of solid CRC, and in second line for 5-FU resistant patients) increased the levels of ceramide 
through activation of serine-palmitoyltransferase and CerS activities, and this ceramide induced growth inhibition via caspase-3 activation in a p53-independent manner [98].

Fenretinide, a synthetic retinoid, induced an increase of ceramide levels in neuroblastoma cells and also in colon cancer cells (HT29 and LoVo). This increase in ceramide was associated with an increase of cell death by a combination of apoptosis and necrosis in a p53 and caspase-independent manner. Interestingly, this effect can be enhanced in combination with safingol, an inhibitor of protein kinase C and SK [99]. Importantly, recent studies showed that fenretinide directly inhibits dihydroceramide desaturase in cells, raising the possibility that many of the actions of this compound may be mediated by its ability to alter ceramide metabolism $[100,101]$.

Using RNAi for CerS6 resulted in a specific decrease in C16-ceramide and protected SW480 cell against TRAIL-mediated apoptosis, while increasing CerS6 expression sensitized SW620 cell to TRAIL. Another way to circumvent CRC cell resistance to TRAIL-mediated apoptosis is by using COX-2 inhibitors to manipulate lipid metabolism. COX-2 inhibition sensitizes human colon carcinoma cells to TRAIL-induced apoptosis by inducing clustering of the TRAIL receptor DR5 at the cell surface and redistribution of the death-inducing signaling complex components into cholesterol-rich and ceramide-rich domains known as caveolae. It is believed that this mechanism enhances the initiation of receptor-mediated signal transduction. This process requires accumulation of arachidonic acid and sequential activation of aSMase for the generation of ceramide within the outer leaflet of the plasma membrane [102].

\subsection{Effects of dietary sphingolipids in different colon cancer models}

The effects of dietary sphingolipids in colon cancer have been studied in different animal models. Here we will review the effects of sphingolipids in chemically-induced colon cancer models such as DHM and AOM, inherited models (APC ${ }^{\text {in } /+}$ mouse), and also colon cancer xenografts.

2.2.1. DMH-induced colon cancer model-Many studies involving dietary sphingolipids (SM, Glucosylceramide, lactosylceramide, ganglioside GD3 extracted from milk, synthetic SM, synthetic dyhydroSM, ceramide analogs, plant sphingolipids) in DMHtreated animals demonstrated a chemotherapeutic as well as a chemopreventive effect. Dillehay et al. showed that CF1 female mice treated with DMH and fed with AIN76A, a diet very low in sphingolipid content, (comprising less than $0.005 \%$ weight) supplemented with milk SM exhibited a significant reduction in the number of ACF when compared with the control group. Tumor incidence in the control group was $47 \%$ while in mice supplemented with SM the incidence was reduced to $20 \%$ [103]. In a follow up study that included a longer time course, SM supplementation also caused a reduction in ACF and the number of aberrant crypts per focus. However, after 40 weeks of treatment, there was no difference in tumor incidence. What was remarkable in this instance was that while all the tumors found in animals fed with AIN76A were adenocarcinomas, at least $31 \%$ of the tumors in mice fed with a diet supplemented with SM were adenomas, suggesting that dietary SM may also suppress the appearance or advancement to more malignant tumors [104]. In an effort to better understand the effects of dietary sphingolipids in colon cancer, Schmeltz et al. [105] studied the effects of chemically synthesized sphingolipids. CF1 female mice treated with DMH were fed the AIN76A diet supplemented with either SM from milk, Npalmitoylsphingomyelin, or N-palmitoyldihydrosphingomyelin for 4 weeks. The number of ACF in the SM-fed groups was significantly lower than in the control group by 54\%, 52\%, and $70 \%$ for milk SM, synthetic SM, and synthetic dihydroSM, respectively. This study confirmed that SM suppressed ACF formation, and that the potency of 
dihydrosphingomyelin did not depend on the 4,5-trans bond of the sphingolipid backbone.

Since most sphingolipids are digested in the small intestine, an analogue of ceramide (Cer- $\beta$ glucuronide) was specifically designed to be delivered to the colon [106]. Cer- $\beta$-glucuronide induced not only a $37 \%$ decrease in the number of ACF but also reduced the number of BrDU-positive cells (20\%) in the lower half of the colonic crypts [106]. Other sphingolipids from milk were also evaluated. Glucosylceramide, lactosylceramide, or ganglioside GD3 induced at least a $40 \%$ decrease in the number of ACF (comparable with the reduction accomplished by SM), and was accompanied by a decrease of proliferation in the colonic crypts. Interestingly, there was no difference in the number of apoptotic cells per crypt among the different groups and the controls [106]. It is important to remark that dietary sphingolipids showed both chemotherapeutic and chemopreventive effects as demonstrated by studies performed by Lemonnier $e t$ al. where they showed DMH-treated mice receiving SM before or after tumor initiation induced a similar decrease in the number of tumors formed and in proliferation in the lower half of the colonic crypts, as well as a similar increase in the number of apoptotic cells [107]. Finally, since plant sphingolipids differ structurally from mammals, their effect in colon cancer has also been evaluated. Soy glucosylceramide (GlcCer), added to the AIN76A diet, decreased colonic cell proliferation in the upper half of the crypts by 50\%, reduced the number of ACF and also reduced the number of adenomas [108].

2.2.2 AOM-induced colon cancer model-The effect of sphingolipids in diet was also tested in animals treated with AOM. Rats treated with $35 \mathrm{mg} / \mathrm{kg}$ of SM orally during the 6 weeks following AOM treatment decreased the number of ACF, specifically in the proximal end of the colon, and also induced a decrease in proliferation in the base of the crypt. This treatment did not affect any of the immune functions tested (antibody formation, delayed type hypersensitivity or natural killer cell cytotoxicity) [109].

Tumor suppressor gene p53 plays an important role in maintaining intestinal homeostasis in the colon by regulating DNA repair and apoptosis. In fact, a very high percentage of colon cancer tumors present mutations in p53, especially in the advanced stages [110]. To evaluate the role of p53 in the effects of dietary sphingolipids on colon cancer, p53 wild type and p53+/- mice were treated with AOM and fed a diet containing $0.1 \%$ SM for 4 weeks. The short-term results indicated that p53 status did not modify the effects of sphingolipids on proliferation and apoptosis. When mice were euthanized 33-38 weeks later, SM administration produced no significant effects on either tumor incidence or size in both genotypes (24\% vs. $38.1 \%)$. However, both tumor incidence and size trended lower with dietary sphingolipid [111], demonstrating that the effect of dietary SM in colon cancer was not p53-dependent.

Sprague-Dawley rats treated with AOM were utilized to indirectly evaluate the effects of sphingolipids in colon cancer using UDCA. This compound was previously shown to exert an antiproliferative and proapoptotic effect in HT29 cells, and this was accompanied by a rapid increase in alk-SMase activity. AOM treated rats showed that UDCA induced a reduction in the number of ACF containing three or more crypts. While AOM treatment by itself reduced mucosal alk-SMase activity, treatment with UDCA increased the activity of both colonic nSMase and aSMase [49].

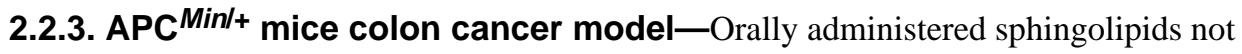
only showed a decrease of ACF and tumors in colon cancer models chemically induced with either DHM or AOM, but their effect has also been described in inherited models such as the $\mathrm{APC}^{\mathrm{Min} /+}$ mouse. $\mathrm{APC}^{\mathrm{Min} /+}$ mice treated with Enigmol, a sphingoid base analogue ((2S,3S, 5S)-2-amino-3,5-dihydroxyoctadecane) that cannot be phosphorylated by SK1 and is poorly $\mathrm{N}$-acetylated, showed a decrease of $50 \%$ in the number of tumors when administered orally 
at $0.025 \%(\mathrm{w} / \mathrm{w})$ of the diet. At these doses, Enigmol had no adverse effects on body weight on any of the liver and kidney biomarkers, even though higher doses could cause dehydration [112].

The effects of plant sphingolipids in colon cancer were also studied in $\mathrm{APC}^{\mathrm{Min} /+}$ mouse, where a diet supplemented with $0.1 \%$ GlcCer reduced the number of adenomas by $70 \%$. The effects of sphingolipids from plants on gene expression in the intestinal mucosal cells on $\mathrm{APC}^{\mathrm{Min} /+}$ mice were analyzed using Affymetrix Gene Chip microarrays. Soy GlcCer affected the expression of at least 96 genes by $\geq 2$ fold in a dose-dependent manner, increasing 32 and decreasing 64. As an example, HIF1a and TCF4, two relevant genes implicated in cancer, showed a significant decrease in mRNA levels that was also confirmed by RT-PCR [108].

2.2.4. Human xenografts-Human xenografts have been used in mice to evaluate the effects of sphingolipids in colon cancer. In particular, xenografts have been mostly used to demonstrate that sphingolipids can enhance and/or mediate the efficacy of anti-cancer drugs. A human colon cancer xenograft HCT116 showed a drastic decrease in tumor volume when treated with a drug that increases the levels of ganglioside GM3 (glycosphingolipid) [113]. SM has been shown to increase the effect of 5-FU (standard first-line chemotherapy for colon cancer) in HT29 human xenografts. In this study, SM was delivered intravenously $(10 \mathrm{mg} /$ day per 7 days) to ensure it readily reached the tumor. Neither 5FU nor SM alone had an effect on tumor growth; however, when used in combination tumor growth was reduced approximately $250 \%$ compared with the untreated control group [87]. In a follow up study, mice bearing HT29, HCT15 and GW-39 xenografts also showed an increase in the tumor response to 5-FU or irinotecan treatment when combined with exogenous SM. This effect was attributed to a reversal of the apoptotic attenuation, without inducing significant hematopoietic, hepatic or renal toxicity [114].

Celecoxib, an inhibitor of COX-2 that induces pro-apoptotic and growth inhibiting effects in cancer cells and activates the sphingolipids pathway was used to treat HCT116 human xenograft in order to confirm results obtained in vitro (in more detail below). This compound inhibited tumor growth [115] accompanied by an increase in the levels of C16:0ceramide in stomach, small intestine, and tumor tissues with no detectable differences in other tissues (brain, lung, heart and testes) [97].

\section{Part III. Sphingolipids in WNT/ $\beta$-catenin pathway}

Wnt pathway mutations are frequent in colon cancer. The central protein in this pathway is $\beta$-catenin, a cytoplasmic/nuclear protein that is regulated by phosphorylation and by proteolysis [116]. Axin, a tumor suppressor protein, acts as the scaffold of this complex interacting directly with $\beta$-catenin, APC (another suppressor protein), CK1 and GSK3a and/ or $\beta$. When this pathway is not activated, CK1 and GSK3a/ $\beta$ sequentially phosphorylate $\beta$ catenin at Ser/Thr residues near the $\mathrm{N}$-terminus. Once $\beta$-catenin is phosphorylated, it is recognized by $\beta$-TrCP, a component of E3 ubiquitin ligase complex, whereby $\beta$-catenin is ubiquitinated and targeted for destruction by the proteasome. Upon activation, the destruction complex is disassembled and, as a consequence, stable non-phosphorylated $\beta$ catenin accumulates and translocates to the nucleus, where it binds to the LEF/TCF transcription factors promoting the transcription of genes that include cyclin D1 and c-myc [117]. Mutations in the APC gene cause FAP, a hereditary cancer syndrome that leads to formation of colon adenomas in early adulthood. Also, most cases of CRC result in acquired loss of both APC alleles. In general, loss of APC function leads to inappropriate stabilization of $\beta$-catenin that induces its mobilization to the nucleus. Mutations in APC are not the only important genetic mutations; other mutations in other proteins of the WNT/ $\beta$-catenin 
pathway occur, including point mutations that remove the regulatory $\mathrm{N}$-terminal Ser/Thr residues in $\beta$-catenin or mutations in Axin2 [116].

The relationship between sphingolipids and the WNT/ $\beta$-catenin pathway has been described in different systems. In Drosophila, downregulation of its unique ceramide synthase protein led to a decrease in the activity of the WNT/ $\beta$-catenin pathway [118]. Also, ASAH1 knockdown in human adrenal cortical cells not only led to a decrease in cell proliferation, but also a decrease of the levels of $\beta$-catenin, together with a decrease of PCNA and cyclin B2 [119]. Another enzyme of sphingolipid metabolism, GCS, upregulated MDR1 (multi drug resistance transporter) expression in the regulation of cancer drug resistance thorough $\beta$-catenin signaling by diminishing its degradation and increasing its translocation to the nucleus [120]. In breast cancer cells, cell confluence induced up-regulation of nSMase2. This up-regulation increased ceramide levels and induced dephosphorylation of $\beta$-catenin on threonine41/serine45, and this effect was prevented using siRNA for nSMase2. Furthermore, addition of long or very long chain ceramides induced dephosphorylation of $\beta$-catenin. The phosphatase implicated in this dephosphorylation was identified as PP1c $\gamma$ as determined by using phosphatase inhibitors and siRNA [121]. On the other hand, and to counter the ceramide effects, S1P in osteoblasts activated the PI3K/AKT/GSK3 $\beta$ pathway leading to the promotion of nuclear translocation of $\beta$-catenin [122].

The effects of sphingolipids in the WNT/ $\beta$-catenin pathway is particularly important in colon cancer cells, since $\beta$-catenin is one of the most important proteins regulating development and homeostasis [123]. One of the most used animal models for colon cancer is the APC ${ }^{\mathrm{Min} /+}$ mice (truncated APC gene product), which are particularly useful not only to study the effect of dietary sphingolipids in adenomas but also to determine their effect in the WNT/ $\beta$-catenin pathway. Dietary sphingolipids induced not only a decrease in the number of adenomas in this model, but also resulted in redistribution of $\beta$-catenin. In this study, mice were fed AIN76A alone, or AIN76A supplemented with either sphingolipids isolated from milk, supplemented with ceramide, or supplemented with a mix of sphingolipids and ceramide to ensure all the metabolites reach all regions of the intestine. After 65 days, the control mice presented an average of 55.8 \pm 4.6 adenomas/mouse, while the other groups displayed a decrease of at least $40 \%$ with a maximum reduction of $50 \%$ in the mice fed a mixture of ceramide and more complex sphingolipids. While $\beta$-catenin distribution in normal mice was mostly restricted to the membrane of the intestinal epithelium, in APC Min/+ $^{\mathrm{N} /+}$ mice $\beta$-catenin localization was more diffuse throughout the cell. The animals fed the sphingolipid enriched diet not only presented a major reduction in the number of adenomas, but $\beta$-catenin was localized to the cellular membranes with a distribution similar to wild type mice [124]. These results were confirmed in vitro using two colon cancer cell lines with APC mutations [125]. While $\beta$-catenin distribution was both cytoplasmic and nuclear in untreated cells, after SPH or bovine ceramide treatment, cells presented an overall reduction in the levels of $\beta$-catenin in both the cytoplasm and nucleus [124]. The effect of sphingolipids on the redistribution of $\beta$-catenin was also observed in CF1 mice treated with DMH. Mice treated with DMH showed an elevated expression of $\beta$-catenin levels with both membrane and cytosolic distribution in cells in the lumen and in the colonic crypt. DMH mice treated with $0.05 \% \mathrm{SM}$ showed reduction and redistribution of $\beta$-catenin to plasma membrane of cells lining the colonic lumen in a manner similar to the untreated mice. The mechanism behind sphingolipid reduction and redistribution of $\beta$-catenin is not very well known; however, the mRNA expression levels of $\beta$-catenin in the colonic mucosa of mice treated with DMH after AIN76A diet with or without SM supplements showed no differences, indicating a post-transcriptional or post-translational modulation [125].

Enigmol (sphingoid base analogue) reduced the number of adenomas by $50 \%$ in APC Min/+ mice when administered orally. The same study showed in vitro treatment with Enigmol 
demonstrated 50\% growth inhibition in 57 out of 60 different cancer cell lines tested [112]. In particular, HT29 cells treated with Enigmol showed cell death associated with caspase-3 activation. HT29 cells exhibit increased of nuclear and cytosolic $\beta$-catenin due to a truncation of the APC gene. After treatment with Enigmol or SPH, $\beta$-catenin nuclear and cytoplasmic expression was mostly diminished as demonstrated by immunofluorescence and Western blot, and redistributed to cell-to-cell boundaries considered a normal location for $\beta$ catenin. The sphingoid base compound not only decreased the total levels of $\beta$-catenin, but also increased the levels of the inactivated p-S33/S37/T41 $\beta$-catenin, probably by activating CK-1 $\alpha$ and GSK-3 $\beta$, as these kinases were also activated after Enigmol treatment [112].

\section{Summary}

In spite of the advances in the understanding of the mechanisms that induce CRC, treatment outcomes have not significantly improved. Over $90 \%$ of CRC patients present a deregulation of the WNT/ $\beta$-catenin signaling pathway, with $30-70 \%$ of those patients involving APC mutations [126]. Since these mutations have been associated with colon cancer initiation, WNT/ $\beta$-catenin has been considered a valid target for chemotherapy. There is increasing evidence that alteration in sphingolipid metabolism can modulate susceptibility to intestinal tumorigenesis and that these effects seem to be mediated, at least in part, by normalizing the levels and distribution of $\beta$-catenin. Indeed, dietary sphingolipids have both chemopreventive and chemotherapeutic effects in colon cancer animal models, and modulation of the enzymes implicated in sphingolipid metabolism seem to change the susceptibility to colon cancer formation as shown in the SK1 ${ }^{-/-}$model following AOM/DSS treatment [39]. In addition, in vitro alteration of both sphingolipids and their metabolism impact proliferation, apoptosis, autophagy and other important biologic functions in colon cancer cells. Research into the in vivo and in vitro effects of sphingolipids have shown that they are mediated in part by modulation of the $\beta$-catenin pathway, underlining the importance of sphingolipids in CRC. Therefore, when taken together, these studies provide a rationale for investigating sphingolipid metabolism as a possible target in both the chemoprevention and chemotherapy of CRC.

\section{Acknowledgments}

This work was supported by the National Institutes of Health grant CA097132. We would like to thank J-P Laigneau for the art work in figure 1.

\section{Abbreviations}

$\begin{array}{ll}\text { CRC } & \text { colorectal cancer } \\ \text { FAP } & \text { Familial Adenomatous Polyposis } \\ \text { AFAP } & \text { Attenuated Familial Adenomatous Polyposis } \\ \text { APC } & \text { Adenomatous Polyposis Coli } \\ \text { K-Ras } & \text { Kirsten rat sarcoma viral oncogene homolog } \\ \text { ACF } & \text { aberrant crypt foci } \\ \text { S1P } & \text { Sphingosine-1-Phosphate } \\ \text { CerS } & \text { Ceramide Synthase } \\ \text { SM } & \text { Sphingomyelin } \\ \text { SMase } & \text { Sphingomyleinase }\end{array}$




\begin{tabular}{|c|c|}
\hline GCS & glucosylceramide synthase \\
\hline SPH & sphingosine \\
\hline CDase & Ceramidase \\
\hline SK & Sphingosine Kinase \\
\hline GLA & Alpha-Galactosidase A \\
\hline SPL & Sphingosine-1-Phosphate Lyase \\
\hline aCDase & acid Ceramidase \\
\hline aSMase & acid Sphingomyelinase \\
\hline nSMase & neutral Sphingomyelinase \\
\hline nCDase & neutral Ceramidase \\
\hline alk-SMase & Alkaline Sphingomyelinase \\
\hline UDCA & Ursodeoxycholic Acid \\
\hline AOM & Azoxymethane \\
\hline DMH & 1.2-Dimethylhydrazine \\
\hline HUVEC & human umbilical vein endothelial cells \\
\hline DSS & Dextran sulfate sodium \\
\hline BrdU & Bromodeoxyuridine \\
\hline DNA & Deoxyribonucleic acid \\
\hline mRNA & messenger ribonucleic acid \\
\hline GlcCer & Glucosylceramide \\
\hline RT-PCR & Reverse Transcriptase- Polymerase Chain Reaction \\
\hline 5-FU & 5-fluorouracil \\
\hline COX-2 & cyclooxygenase- 2 \\
\hline DMS & N, N-Dimethylsphingosine \\
\hline ERK & Extracellular-signal-regulated kinase \\
\hline bSMase & bacterial Sphingomyelinase \\
\hline TNF & Tumor Necrosis Factor \\
\hline PCNA & Proliferating cell nuclear antigen \\
\hline SiRNA & small interference ribonucleic acid \\
\hline TRAIL & TNF-Related Apoptosis-Inducing Ligand \\
\hline CK1 & Casein Kinase 1 \\
\hline GSK3 & Glycogen Synthase Kinase 3 \\
\hline$\beta-\operatorname{TrCP}$ & Beta -Transducin Repeat Containing Protein \\
\hline LEF/TCF & Lymphoid Enhancer Factor/T-Cell Factor \\
\hline PP1c & Protein phosphatase 1c \\
\hline MDR1 & Multi drug resistance transporter \\
\hline
\end{tabular}




\section{References}

1. Ferlay J, Shin HR, Bray F, Forman D, Mathers C, Parkin DM. Estimates of worldwide burden of cancer in 2008: GLOBOCAN 2008. International journal of cancer Journal international du cancer. 2010; 127(12):2893-2917. Epub 2011/02/26. [PubMed: 21351269]

2. Figures SACF. Atlanta: American Cancer Society; 2013.

3. Johns LE, Houlston RS. A systematic review and meta-analysis of familial colorectal cancer risk. The American journal of gastroenterology. 2001; 96(10):2992-3003. Epub 2001/11/06. [PubMed: 11693338]

4. Miyoshi Y, Ando H, Nagase H, Nishisho I, Horii A, Miki Y, et al. Germ-line mutations of the APC gene in 53 familial adenomatous polyposis patients. Proceedings of the National Academy of Sciences of the United States of America. 1992; 89(10):4452-4456. Epub 1992/05/15. [PubMed: 1316610]

5. Brensinger JD, Laken SJ, Luce MC, Powell SM, Vance GH, Ahnen DJ, et al. Variable phenotype of familial adenomatous polyposis in pedigrees with 3' mutation in the APC gene. Gut. 1998; 43(4): 548-552. Epub 1998/11/21. [PubMed: 9824584]

6. Steinke V, Engel C, Buttner R, Schackert HK, Schmiegel WH, Propping P. Hereditary nonpolyposis colorectal cancer (HNPCC)/Lynch syndrome. Deutsches Arzteblatt international. 2013; 110(3):3238. Epub 2013/02/16. [PubMed: 23413378]

7. Seshagiri S. The burden of faulty proofreading in colon cancer. Nature genetics. $2013 ; 45(2): 121-$ 122. Epub 2013/01/30. [PubMed: 23358219]

8. Yamaguchi S, Ogata H, Katsumata D, Nakajima M, Fujii T, Tsutsumi S, et al. MUTYH-associated colorectal cancer and adenomatous polyposis. Surgery today. 2013 Epub 2013/04/23.

9. Lichtenstein P, Holm NV, Verkasalo PK, Iliadou A, Kaprio J, Koskenvuo M, et al. Environmental and heritable factors in the causation of cancer--analyses of cohorts of twins from Sweden, Denmark, and Finland. The New England journal of medicine. 2000; 343(2):78-85. Epub 2000/07/13. [PubMed: 10891514]

10. Radtke F, Clevers H. Self-renewal and cancer of the gut: two sides of a coin. Science. 2005; 307(5717):1904-1909. Epub 2005/03/26. [PubMed: 15790842]

11. Sancho E, Batlle E, Clevers H. Signaling pathways in intestinal development and cancer. Annual review of cell and developmental biology. 2004; 20:695-723. Epub 2004/10/12.

12. Fearon ER, Vogelstein B. A genetic model for colorectal tumorigenesis. Cell. 1990; 61(5):759_ 767. Epub 1990/06/01. [PubMed: 2188735]

13. Cheng L, Lai MD. Aberrant crypt foci as microscopic precursors of colorectal cancer. World journal of gastroenterology: WJG. 2003; 9(12):2642-2649. Epub 2003/12/12. [PubMed: 14669304]

14. Nucci MR, Robinson CR, Longo P, Campbell P, Hamilton SR. Phenotypic and genotypic characteristics of aberrant crypt foci in human colorectal mucosa. Human pathology. 1997; 28(12): 1396-1407. Epub 1998/01/07. [PubMed: 9416697]

15. Hannun YA. Functions of ceramide in coordinating cellular responses to stress. Science. 1996; 274(5294):1855-1859. Epub 1996/12/13. [PubMed: 8943189]

16. Nikolova-Karakashian MN, Rozenova KA. Ceramide in stress response. Advances in experimental medicine and biology. 2010; 688:86-108. Epub 2010/10/06. [PubMed: 20919648]

17. Stancevic B, Kolesnick R. Ceramide-rich platforms in transmembrane signaling. FEBS letters. 2010; 584(9):1728-1740. Epub 2010/02/25. [PubMed: 20178791]

18. El Alwani M, Wu BX, Obeid LM, Hannun YA. Bioactive sphingolipids in the modulation of the inflammatory response. Pharmacology \& therapeutics. 2006; 112(1):171-183. Epub 2006/06/09. [PubMed: 16759708]

19. Hannun YA, Obeid LM. Many ceramides. The Journal of biological chemistry. 2011; 286(32): 27855-27862. Epub 2011/06/23. [PubMed: 21693702]

20. Hannun YA, Obeid LM. Principles of bioactive lipid signalling: lessons from sphingolipids. Nature reviews Molecular cell biology. 2008; 9(2):139-150. Epub 2008/01/25. 
21. Maceyka M, Milstien S, Spiegel S. Sphingosine-1-phosphate: the Swiss army knife of sphingolipid signaling. Journal of lipid research. 2009; 50(Suppl):S272-S276. Epub 2008/11/07. [PubMed: 18987387]

22. Ogretmen B, Hannun YA. Biologically active sphingolipids in cancer pathogenesis and treatment. Nature reviews Cancer. 2004; 4(8):604-616. Epub 2004/08/03.

23. Zeidan YH, Hannun YA. Translational aspects of sphingolipid metabolism. Trends in molecular medicine. 2007; 13(8):327-336. Epub 2007/06/26. [PubMed: 17588815]

24. Furuya H, Shimizu Y, Kawamori T. Sphingolipids in cancer. Cancer metastasis reviews. 2011; 30(3-4):567-576. Epub 2011/10/19. [PubMed: 22005951]

25. Saddoughi SA, Ogretmen B. Diverse functions of ceramide in cancer cell death and proliferation. Advances in cancer research. 2013; 117:37-58. Epub 2013/01/08. [PubMed: 23290776]

26. Mullen TD, Hannun YA, Obeid LM. Ceramide synthases at the centre of sphingolipid metabolism and biology. The Biochemical journal. 2012; 441(3):789-802. Epub 2012/01/18. [PubMed: 22248339]

27. Henry B, Ziobro R, Becker KA, Kolesnick R, Gulbins E. Acid sphingomyelinase. Handbook of experimental pharmacology. 2013; 215:77-88. Epub 2013/04/13. [PubMed: 23579450]

28. Airola MV, Hannun YA. Sphingolipid metabolism and neutral sphingomyelinases. Handbook of experimental pharmacology. 2013; 215:57-76. Epub 2013/04/13. [PubMed: 23579449]

29. Holthuis JC, Luberto C. Tales and mysteries of the enigmatic sphingomyelin synthase family. Advances in experimental medicine and biology. 2010; 688:72-85. Epub 2010/10/06. [PubMed: 20919647]

30. Liu YY, Hill RA, Li YT. Ceramide glycosylation catalyzed by glucosylceramide synthase and cancer drug resistance. Advances in cancer research. 2013; 117:59-89. Epub 2013/01/08. [PubMed: 23290777]

31. Heffernan-Stroud LA, Obeid LM. Sphingosine kinase 1 in cancer. Advances in cancer research. 2013; 117:201-235. Epub 2013/01/08. [PubMed: 23290781]

32. Bartke N, Hannun YA. Bioactive sphingolipids: metabolism and function. Journal of lipid research. 2009; 50(Suppl):S91-S96. Epub 2008/11/20. [PubMed: 19017611]

33. Gault CR, Obeid LM, Hannun YA. An overview of sphingolipid metabolism: from synthesis to breakdown. Advances in experimental medicine and biology. 2010; 688:1-23. Epub 2010/10/06. [PubMed: 20919643]

34. Canals D, Hannun YA. Novel chemotherapeutic drugs in sphingolipid cancer research. Handbook of experimental pharmacology. 2013; 215:211-238. Epub 2013/04/13. [PubMed: 23579458]

35. Alekseenko AV. The potential role for sphingolipids in neuropathogenesis of Alzheimer's disease. Biomeditsinskaia khimiia. 2013; 59(1):25-50. Epub 2013/05/09. [PubMed: 23650721]

36. Hornemann T, Worgall TS. Sphingolipids and atherosclerosis. Atherosclerosis. 2013; 226(1):1628. Epub 2012/10/19. [PubMed: 23075523]

37. Becker KA, Henry B, Ziobro R, Riethmuller J, Gulbins E. Lipids in cystic fibrosis. Expert review of respiratory medicine. 2011; 5(4):527-535. Epub 2011/08/24. [PubMed: 21859272]

38. Flowers M, Fabrias G, Delgado A, Casas J, Abad JL, Cabot MC. C6-ceramide and targeted inhibition of acid ceramidase induce synergistic decreases in breast cancer cell growth. Breast cancer research and treatment. 2012; 133(2):447-458. Epub 2011/09/22. [PubMed: 21935601]

39. Kawamori T, Kaneshiro T, Okumura M, Maalouf S, Uflacker A, Bielawski J, et al. Role for sphingosine kinase 1 in colon carcinogenesis. FASEB journal: official publication of the Federation of American Societies for Experimental Biology. 2009; 23(2):405-414. Epub 2008/10/01. [PubMed: 18824518]

40. Duan RD, Nilsson A. Metabolism of sphingolipids in the gut and its relation to inflammation and cancer development. Progress in lipid research. 2009; 48(1):62-72. Epub 2008/11/26. [PubMed: 19027789]

41. Danielsen EM, Hansen GH. Lipid raft organization and function in the small intestinal brush border. Journal of physiology and biochemistry. 2008; 64(4):377-382. Epub 2009/04/28. [PubMed: 19391463]

42. Wu J, Liu F, Nilsson A, Duan RD. Pancreatic trypsin cleaves intestinal alkaline sphingomyelinase from mucosa and enhances the sphingomyelinase activity. American journal of physiology 
Gastrointestinal and liver physiology. 2004; 287(5):G967-G973. Epub 2004/06/19. [PubMed: 15205117]

43. Hertervig E, Nilsson A, Nilbert M, Duan RD. Reduction in alkaline sphingomyelinase in colorectal tumorigenesis is not related to the APC gene mutation. International journal of colorectal disease. 2003; 18(4):309-313. Epub 2003/05/30. [PubMed: 12774245]

44. Hertervig E, Nilsson A, Cheng Y, Duan RD. Purified intestinal alkaline sphingomyelinase inhibits proliferation without inducing apoptosis in HT-29 colon carcinoma cells. Journal of cancer research and clinical oncology. 2003; 129(10):577-582. Epub 2003/08/16. [PubMed: 12920578]

45. Hertervig E, Nilsson A, Nyberg L, Duan RD. Alkaline sphingomyelinase activity is decreased in human colorectal carcinoma. Cancer. 1997; 79(3):448-453. Epub 1997/02/01. [PubMed: 9028353]

46. Sjoqvist U, Hertervig E, Nilsson A, Duan RD, Ost A, Tribukait B, et al. Chronic colitis is associated with a reduction of mucosal alkaline sphingomyelinase activity. Inflammatory bowel diseases. 2002; 8(4):258-263. Epub 2002/07/20. [PubMed: 12131609]

47. Cheng Y, Tauschel HD, Nilsson A, Duan RD. Ursodeoxycholic acid increases the activities of alkaline sphingomyelinase and caspase-3 in the rat colon. Scandinavian journal of gastroenterology. 1999; 34(9):915-920. Epub 1999/10/16. [PubMed: 10522612]

48. Andersson D, Liu JJ, Nilsson A, Duan RD. Ursolic acid inhibits proliferation and stimulates apoptosis in HT29 cells following activation of alkaline sphingomyelinase. Anticancer research. 2003; 23(4):3317-3322. Epub 2003/08/21. [PubMed: 12926069]

49. Andersson D, Cheng Y, Duan RD. Ursolic acid inhibits the formation of aberrant crypt foci and affects colonic sphingomyelin hydrolyzing enzymes in azoxymethane-treated rats. Journal of cancer research and clinical oncology. 2008; 134(1):101-107. Epub 2007/07/03. [PubMed: 17605045]

50. Rubin DT, Lashner BA. Will a 5-ASA a day keep the cancer (and dysplasia) away? The American journal of gastroenterology. 2005; 100(6):1354-1356. Epub 2005/06/03. [PubMed: 15929769]

51. Earnest DL, Holubec H, Wali RK, Jolley CS, Bissonette M, Bhattacharyya AK, et al. Chemoprevention of azoxymethane-induced colonic carcinogenesis by supplemental dietary ursodeoxycholic acid. Cancer research. 1994; 54(19):5071-5074. Epub 1994/10/01. [PubMed: 7923119]

52. Duan RD. Alkaline sphingomyelinase: an old enzyme with novel implications. Biochimica et biophysica acta. 2006; 1761(3):281-291. Epub 2006/04/25. [PubMed: 16631405]

53. Fukuda Y, Kihara A, Igarashi Y. Distribution of sphingosine kinase activity in mouse tissues: contribution of SPHK1. Biochemical and biophysical research communications. 2003; 309(1): 155-160. Epub 2003/08/29. [PubMed: 12943676]

54. Kawamori T, Osta W, Johnson KR, Pettus BJ, Bielawski J, Tanaka T, et al. Sphingosine kinase 1 is up-regulated in colon carcinogenesis. FASEB journal: official publication of the Federation of American Societies for Experimental Biology. 2006; 20(2):386-388. Epub 2005/12/02. [PubMed: 16319132]

55. Kohno M, Momoi M, Oo ML, Paik JH, Lee YM, Venkataraman K, et al. Intracellular role for sphingosine kinase 1 in intestinal adenoma cell proliferation. Molecular and cellular biology. 2006; 26(19):7211-7223. Epub 2006/09/19. [PubMed: 16980623]

56. Liang J, Nagahashi M, Kim EY, Harikumar KB, Yamada A, Huang WC, et al. Sphingosine-1phosphate links persistent STAT3 activation, chronic intestinal inflammation, and development of colitis-associated cancer. Cancer cell. 2013; 23(1):107-120. Epub 2013/01/01. [PubMed: 23273921]

57. Eisenhoffer GT, Loftus PD, Yoshigi M, Otsuna H, Chien CB, Morcos PA, et al. Crowding induces live cell extrusion to maintain homeostatic cell numbers in epithelia. Nature. 2012; 484(7395): 546-549. Epub 2012/04/17. [PubMed: 22504183]

58. Oskouian B, Sooriyakumaran P, Borowsky AD, Crans A, Dillard-Telm L, Tam YY, et al. Sphingosine-1-phosphate lyase potentiates apoptosis via p53-and p38-dependent pathways and is down-regulated in colon cancer. Proceedings of the National Academy of Sciences of the United States of America. 2006; 103(46):17384-17389. Epub 2006/11/09. [PubMed: 17090686]

59. Oskouian B, Saba J. Sphingosine-1-phosphate metabolism and intestinal tumorigenesis: lipid signaling strikes again. Cell Cycle. 2007; 6(5):522-527. Epub 2007/03/16. [PubMed: 17361098] 
60. Duan RD, Bergman T, Xu N, Wu J, Cheng Y, Duan J, et al. Identification of human intestinal alkaline sphingomyelinase as a novel ecto-enzyme related to the nucleotide phosphodiesterase family. The Journal of biological chemistry. 2003; 278(40):38528-38536. Epub 2003/07/30. [PubMed: 12885774]

61. Olsson M, Duan RD, Ohlsson L, Nilsson A. Rat intestinal ceramidase: purification, properties, and physiological relevance. American journal of physiology Gastrointestinal and liver physiology. 2004; 287(4):G929-G937. Epub 2004/06/26. [PubMed: 15217782]

62. Ohlsson L, Palmberg C, Duan RD, Olsson M, Bergman T, Nilsson A. Purification and characterization of human intestinal neutral ceramidase. Biochimie. 2007; 89(8):950-960. Epub 2007/05/04. [PubMed: 17475390]

63. Duan RD, Cheng Y, Yang L, Ohlsson L, Nilsson A. Evidence for specific ceramidase present in the intestinal contents of rats and humans. Lipids. 2001; 36(8):807-812. Epub 2001/10/11. [PubMed: 11592731]

64. Lundgren P, Nilsson A, Duan RD. Distribution and properties of neutral ceramidase activity in rat intestinal tract. Digestive diseases and sciences. 2001; 46(4):765-772. Epub 2001/05/02. [PubMed: 11330410]

65. Kono M, Dreier JL, Ellis JM, Allende ML, Kalkofen DN, Sanders KM, et al. Neutral ceramidase encoded by the Asah2 gene is essential for the intestinal degradation of sphingolipids. The Journal of biological chemistry. 2006; 281(11):7324-7331. Epub 2005/12/29. [PubMed: 16380386]

66. Liu YY, Han TY, Giuliano AE, Cabot MC. Expression of glucosylceramide synthase, converting ceramide to glucosylceramide, confers adriamycin resistance in human breast cancer cells. The Journal of biological chemistry. 1999; 274(2):1140-1146. Epub 1999/01/05. [PubMed: 9873062]

67. Lucci A, Cho WI, Han TY, Giuliano AE, Morton DL, Cabot MC. Glucosylceramide: a marker for multiple-drug resistant cancers. Anticancer research. 1998; 18(1B):475-480. Epub 1998/05/06. [PubMed: 9568165]

68. Liu YY, Han TY, Giuliano AE, Cabot MC. Ceramide glycosylation potentiates cellular multidrug resistance. FASEB journal: official publication of the Federation of American Societies for Experimental Biology. 2001; 15(3):719-730. Epub 2001/03/22. [PubMed: 11259390]

69. Kovbasnjuk O, Mourtazina R, Baibakov B, Wang T, Elowsky C, Choti MA, et al. The glycosphingolipid globotriaosylceramide in the metastatic transformation of colon cancer. Proceedings of the National Academy of Sciences of the United States of America. 2005; 102(52): 19087-19092. Epub 2005/12/21. [PubMed: 16365318]

70. Uchida Y, Murata S, Schmuth M, Behne MJ, Lee JD, Ichikawa S, et al. Glucosylceramide synthesis and synthase expression protect against ceramide-induced stress. Journal of lipid research. 2002; 43(8):1293-1302. Epub 2002/08/15. [PubMed: 12177173]

71. Vesper H, Schmelz EM, Nikolova-Karakashian MN, Dillehay DL, Lynch DV, Merrill AH Jr. Sphingolipids in food and the emerging importance of sphingolipids to nutrition. The Journal of nutrition. 1999; 129(7):1239-1250. Epub 1999/07/08. [PubMed: 10395583]

72. Dudeja PK, Dahiya R, Brasitus TA. The role of sphingomyelin synthetase and sphingomyelinase in 1,2-dimethylhydrazine-induced lipid alterations of rat colonic plasma membranes. Biochimica et biophysica acta. 1986; 863(2):309-312. Epub 1986/12/16. [PubMed: 3024722]

73. Dahiya R, Dudeja PK, Brasitus TA. Premalignant alterations in the glycosphingolipids of small intestinal mucosa of rats treated with 1,2-dimethylhydrazine. Lipids. 1988; 23(5):445-451. Epub 1988/05/01. [PubMed: 3412124]

74. Ahn EH, Schroeder JJ. Sphingoid bases and ceramide induce apoptosis in HT-29 and HCT-116 human colon cancer cells. Exp Biol Med (Maywood). 2002; 227(5):345-353. Epub 2002/04/27. [PubMed: 11976405]

75. Hartmann D, Lucks J, Fuchs S, Schiffmann S, Schreiber Y, Ferreiros N, et al. Long chain ceramides and very long chain ceramides have opposite effects on human breast and colon cancer cell growth. The international journal of biochemistry \& cell biology. 2012; 44(4):620-628. Epub 2012/01/11. [PubMed: 22230369]

76. Fillet M, Cren-Olive C, Renert AF, Piette J, Vandermoere F, Rolando C, et al. Differential expression of proteins in response to ceramide-mediated stress signal in colon cancer cells by 2-D 
gel electrophoresis and MALDI-TOF-MS. Journal of proteome research. 2005; 4(3):870-880. Epub 2005/06/15. [PubMed: 15952734]

77. Koizumi K, Shimizu S, Koizumi KT, Nishida K, Sato C, Ota K, et al. Rapid isolation and lipid characterization of plasma membranes from normal and malignant lymphoid cells of mouse. Biochimica et biophysica acta. 1981; 649(2):393-403. Epub 1981/12/07. [PubMed: 7317406]

78. Van Blitterswijk WJ, Hilkmann H, Hengeveld T. Differences in membrane lipid composition and fluidity of transplanted GRSL lymphoma cells, depending on their site of growth in the mouse. Biochimica et biophysica acta. 1984; 778(3):521-529. Epub 1984/12/19. [PubMed: 6509050]

79. Morad SA, Madigan JP, Levin JC, Abdelmageed N, Karimi R, Rosenberg DW, et al. Tamoxifen magnifies therapeutic impact of ceramide in human colorectal cancer cells independent of p53. Biochemical pharmacology. 2013; 85(8):1057-1065. Epub 2013/01/29. [PubMed: 23353700]

80. Ahn EH, Schroeder JJ. Induction of apoptosis by sphingosine, sphinganine, and C(2)-ceramide in human colon cancer cells, but not by C(2)-dihydroceramide. Anticancer research. 2010; 30(7): 2881-2884. Epub 2010/08/05. [PubMed: 20683027]

81. Scarlatti F, Bauvy C, Ventruti A, Sala G, Cluzeaud F, Vandewalle A, et al. Ceramide-mediated macroautophagy involves inhibition of protein kinase B and up-regulation of beclin 1 . The Journal of biological chemistry. 2004; 279(18):18384-18391. Epub 2004/02/19. [PubMed: 14970205]

82. Sweeney EA, Sakakura C, Shirahama T, Masamune A, Ohta H, Hakomori S, et al. Sphingosine and its methylated derivative N,N-dimethylsphingosine (DMS) induce apoptosis in a variety of human cancer cell lines. International journal of cancer Journal international du cancer. 1996; 66(3):358-366. Epub 1996/05/03. [PubMed: 8621258]

83. Dindo D, Dahm F, Szulc Z, Bielawska A, Obeid LM, Hannun YA, et al. Cationic long-chain ceramide LCL-30 induces cell death by mitochondrial targeting in SW403 cells. Molecular cancer therapeutics. 2006; 5(6):1520-1529. Epub 2006/07/05. [PubMed: 16818511]

84. Sugawara T, Zaima N, Yamamoto A, Sakai S, Noguchi R, Hirata T. Isolation of sphingoid bases of sea cucumber cerebrosides and their cytotoxicity against human colon cancer cells. Bioscience, biotechnology, and biochemistry. 2006; 70(12):2906-2912. Epub 2006/12/08.

85. Thamilselvan V, Li W, Sumpio BE, Basson MD. Sphingosine-1-phosphate stimulates human Caco-2 intestinal epithelial proliferation via p38 activation and activates ERK by an independent mechanism. In vitro cellular \& developmental biology Animal. 2002; 38(4):246-253. Epub 2002/08/29. [PubMed: 12197778]

86. Visentin B, Vekich JA, Sibbald BJ, Cavalli AL, Moreno KM, Matteo RG, et al. Validation of an anti-sphingosine-1-phosphate antibody as a potential therapeutic in reducing growth, invasion, and angiogenesis in multiple tumor lineages. Cancer cell. 2006; 9(3):225-238. Epub 2006/03/15. [PubMed: 16530706]

87. Modrak DE, Lew W, Goldenberg DM, Blumenthal R. Sphingomyelin potentiates chemotherapy of human cancer xenografts. Biochemical and biophysical research communications. 2000; 268(2): 603-606. Epub 2000/02/19. [PubMed: 10679250]

88. Kok JW, Veldman RJ, Klappe K, Koning H, Filipeanu CM, Muller M. Differential expression of sphingolipids in MRP1 overexpressing HT29 cells. International journal of cancer Journal international du cancer. 2000; 87(2):172-178. Epub 2000/06/22. [PubMed: 10861470]

89. Benedict CA, Ware CF. TRAIL: not just for tumors anymore? The Journal of experimental medicine. 2012; 209(11):1903-1906. Epub 2012/10/24. [PubMed: 23091198]

90. Voelkel-Johnson C, Hannun YA, El-Zawahry A. Resistance to TRAIL is associated with defects in ceramide signaling that can be overcome by exogenous C6-ceramide without requiring downregulation of cellular FLICE inhibitory protein. Molecular cancer therapeutics. 2005; 4(9):1320 1327. Epub 2005/09/20. [PubMed: 16170023]

91. White-Gilbertson S, Mullen T, Senkal C, Lu P, Ogretmen B, Obeid L, et al. Ceramide synthase 6 modulates TRAIL sensitivity and nuclear translocation of active caspase- 3 in colon cancer cells. Oncogene. 2009; 28(8):1132-1141. Epub 2009/01/13. [PubMed: 19137010]

92. Selzner M, Bielawska A, Morse MA, Rudiger HA, Sindram D, Hannun YA, et al. Induction of apoptotic cell death and prevention of tumor growth by ceramide analogues in metastatic human colon cancer. Cancer research. 2001; 61(3):1233-1240. Epub 2001/02/28. [PubMed: 11221856] 
93. Veldman RJ, Klappe K, Hoekstra D, Kok JW. Metabolism and apoptotic properties of elevated ceramide in HT29rev cells. The Biochemical journal. 1998; 331(Pt-2):563-569. Epub 1998/06/11. [PubMed: 9531498]

94. Colell A, Morales A, Fernandez-Checa JC, Garcia-Ruiz C. Ceramide generated by acidic sphingomyelinase contributes to tumor necrosis factor-alpha-mediated apoptosis in human colon HT-29 cells through glycosphingolipids formation. Possible role of ganglioside GD3. FEBS letters. 2002; 526(1-3):135-141. Epub 2002/09/05. [PubMed: 12208520]

95. Jaiswal AS, Narayan S. Reduced levels of the adenomatous polyposis coli (APC) protein are associated with ceramide-induced apoptosis of colon cancer cells. Journal of cancer research and clinical oncology. 2004; 130(12):695-703. Epub 2004/09/02. [PubMed: 15340841]

96. Nemoto S, Nakamura M, Osawa Y, Kono S, Itoh Y, Okano Y, et al. Sphingosine kinase isoforms regulate oxaliplatin sensitivity of human colon cancer cells through ceramide accumulation and Akt activation. The Journal of biological chemistry. 2009; 284(16):10422-10432. Epub 2009/02/26. [PubMed: 19240026]

97. Schiffmann S, Ziebell S, Sandner J, Birod K, Deckmann K, Hartmann D, et al. Activation of ceramide synthase 6 by celecoxib leads to a selective induction of C16:0-ceramide. Biochemical pharmacology. 2010; 80(11):1632-1640. Epub 2010/08/26. [PubMed: 20735991]

98. Chauvier D, Morjani H, Manfait M. Ceramide involvement in homocamptothecin-and camptothecin-induced cytotoxicity and apoptosis in colon HT29 cells. International journal of oncology. 2002; 20(4):855-863. Epub 2002/03/15. [PubMed: 11894136]

99. Maurer BJ, Melton L, Billups C, Cabot MC, Reynolds CP. Synergistic cytotoxicity in solid tumor cell lines between $\mathrm{N}$-(4-hydroxyphenyl)retinamide and modulators of ceramide metabolism. Journal of the National Cancer Institute. 2000; 92(23):1897-1909. Epub 2000/12/07. [PubMed: 11106681]

100. Wang H, Maurer BJ, Liu YY, Wang E, Allegood JC, Kelly S, et al. N-(4Hydroxyphenyl)retinamide increases dihydroceramide and synergizes with dimethylsphingosine to enhance cancer cell killing. Molecular cancer therapeutics. 2008; 7(9):2967-2976. Epub 2008/09/16. [PubMed: 18790777]

101. Rahmaniyan M, Curley RW Jr, Obeid LM, Hannun YA, Kraveka JM. Identification of dihydroceramide desaturase as a direct in vitro target for fenretinide. The Journal of biological chemistry. 2011; 286(28):24754-24764. Epub 2011/05/06. [PubMed: 21543327]

102. Martin S, Phillips DC, Szekely-Szucs K, Elghazi L, Desmots F, Houghton JA. Cyclooxygenase-2 inhibition sensitizes human colon carcinoma cells to TRAIL-induced apoptosis through clustering of DR5 and concentrating death-inducing signaling complex components into ceramide-enriched caveolae. Cancer research. 2005; 65(24):11447-11458. Epub 2005/12/17. [PubMed: 16357153]

103. Dillehay DL, Webb SK, Schmelz EM, Merrill AH Jr. Dietary sphingomyelin inhibits 1,2dimethylhydrazine-induced colon cancer in CF1 mice. The Journal of nutrition. 1994; 124(5): 615-620. Epub 1994/05/01. [PubMed: 8169652]

104. Schmelz EM, Dillehay DL, Webb SK, Reiter A, Adams J, Merrill AH Jr. Sphingomyelin consumption suppresses aberrant colonic crypt foci and increases the proportion of adenomas versus adenocarcinomas in CF1 mice treated with 1,2-dimethylhydrazine: implications for dietary sphingolipids and colon carcinogenesis. Cancer research. 1996; 56(21):4936-4941. Epub 1996/11/01. [PubMed: 8895747]

105. Schmelz EM, Bushnev AS, Dillehay DL, Liotta DC, Merrill AH Jr. Suppression of aberrant colonic crypt foci by synthetic sphingomyelins with saturated or unsaturated sphingoid base backbones. Nutrition and cancer. 1997; 28(1):81-85. Epub 1997/01/01. [PubMed: 9200154]

106. Schmelz EM, Bushnev AS, Dillehay DL, Sullards MC, Liotta DC, Merrill AH Jr. Ceramide-betaD-glucuronide: synthesis, digestion, and suppression of early markers of colon carcinogenesis. Cancer research. 1999; 59(22):5768-5772. Epub 1999/12/03. [PubMed: 10582697]

107. Lemonnier LA, Dillehay DL, Vespremi MJ, Abrams J, Brody E, Schmelz EM. Sphingomyelin in the suppression of colon tumors: prevention versus intervention. Archives of biochemistry and biophysics. 2003; 419(2):129-138. Epub 2003/11/01. [PubMed: 14592456] 
108. Symolon H, Schmelz EM, Dillehay DL, Merrill AH Jr. Dietary soy sphingolipids suppress tumorigenesis and gene expression in 1,2-dimethylhydrazine-treated CF1 mice and ApcMin/+ mice. The Journal of nutrition. 2004; 134(5):1157-1161. Epub 2004/04/29. [PubMed: 15113963]

109. Exon JH, South EH. Effects of sphingomyelin on aberrant colonic crypt foci development, colon crypt cell proliferation and immune function in an aging rat tumor model. Food and chemical toxicology: an international journal published for the British Industrial Biological Research Association. 2003; 41(4):471-476. Epub 2003/03/05. [PubMed: 12615120]

110. Baker SJ, Preisinger AC, Jessup JM, Paraskeva C, Markowitz S, Willson JK, et al. p53 gene mutations occur in combination with $17 \mathrm{p}$ allelic deletions as late events in colorectal tumorigenesis. Cancer research. 1990; 50(23):7717-7722. Epub 1990/12/01. [PubMed: 2253215]

111. Hu Y, Le Leu RK, Belobrajdic D, Young GP. The potential of sphingomyelin as a chemopreventive agent in AOM-induced colon cancer model: wild-type and p53+/- mice. Molecular nutrition \& food research. 2008; 52(5):558-566. Epub 2008/03/08. [PubMed: 18324704]

112. Symolon H, Bushnev A, Peng Q, Ramaraju H, Mays SG, Allegood JC, et al. Enigmol: a novel sphingolipid analogue with anticancer activity against cancer cell lines and in vivo models for intestinal and prostate cancer. Molecular cancer therapeutics. 2011; 10(4):648-657. Epub 2011/03/15. [PubMed: 21398423]

113. Nojiri H, Yamana H, Shirouzu G, Suzuki T, Isono H. Glycotherapy for cancer: remodeling of ganglioside pattern as an effective approach for cancer therapy. Cancer detection and prevention. 2002; 26(2):114-120. Epub 2002/07/10. [PubMed: 12102145]

114. Modrak DE, Rodriguez MD, Goldenberg DM, Lew W, Blumenthal RD. Sphingomyelin enhances chemotherapy efficacy and increases apoptosis in human colonic tumor xenografts. International journal of oncology. 2002; 20(2):379-384. Epub 2002/01/15. [PubMed: 11788905]

115. Schiffmann S, Maier TJ, Wobst I, Janssen A, Corban-Wilhelm H, Angioni C, et al. The antiproliferative potency of celecoxib is not a class effect of coxibs. Biochemical pharmacology. 2008; 76(2):179-187. Epub 2008/06/13. [PubMed: 18547544]

116. Clevers H, Nusse R. Wnt/beta-catenin signaling and disease. Cell. 2012; 149(6):1192-1205. Epub 2012/06/12. [PubMed: 22682243]

117. Clevers H. Wnt/beta-catenin signaling in development and disease. Cell. 2006; 127(3):469-480. Epub 2006/11/04. [PubMed: 17081971]

118. Pepperl J, Reim G, Luthi U, Kaech A, Hausmann G, Basler K. Sphingolipid depletion impairs endocytic traffic and inhibits Wingless signaling. Mechanisms of development. 2013 Epub 2013/05/15.

119. Lucki NC, Bandyopadhyay S, Wang E, Merrill AH, Sewer MB. Acid ceramidase (ASAH1) is a global regulator of steroidogenic capacity and adrenocortical gene expression. Mol Endocrinol. 2012; 26(2):228-243. Epub 2012/01/21. [PubMed: 22261821]

120. Liu YY, Gupta V, Patwardhan GA, Bhinge K, Zhao Y, Bao J, et al. Glucosylceramide synthase upregulates MDR1 expression in the regulation of cancer drug resistance through cSrc and betacatenin signaling. Molecular cancer. 2010; 9:145. Epub 2010/06/15. [PubMed: 20540746]

121. Marchesini N, Jones JA, Hannun YA. Confluence induced threonine41/serine45 phospho-betacatenin dephosphorylation via ceramide-mediated activation of PP1cgamma. Biochimica et biophysica acta. 2007; 1771(12):1418-1428. Epub 2007/11/13. [PubMed: 17996206]

122. Matsuzaki E, Hiratsuka S, Hamachi T, Takahashi-Yanaga F, Hashimoto Y, Higashi K, et al. Sphingosine-1-phosphate promotes the nuclear translocation of beta-catenin and thereby induces osteoprotegerin gene expression in osteoblast-like cell lines. Bone. 2013 Epub 2013/04/25.

123. Ahmed I, Chandrakesan P, Tawfik O, Xia L, Anant S, Umar S. Critical roles of Notch and Wnt/ beta-catenin pathways in the regulation of hyperplasia and/or colitis in response to bacterial infection. Infection and immunity. 2012; 80(9):3107-3121. Epub 2012/06/20. [PubMed: 22710872]

124. Schmelz EM, Roberts PC, Kustin EM, Lemonnier LA, Sullards MC, Dillehay DL, et al. Modulation of intracellular beta-catenin localization and intestinal tumorigenesis in vivo and in vitro by sphingolipids. Cancer research. 2001; 61(18):6723-6729. Epub 2001/09/18. [PubMed: 11559543] 
125. Simon KW, Roberts PC, Vespremi MJ, Manchen S, Schmelz EM. Regulation of beta-catenin and connexin-43 expression: targets for sphingolipids in colon cancer prevention. Molecular nutrition $\&$ food research. 2009; 53(3):332-340. Epub 2008/10/08. [PubMed: 18837472]

126. Luchtenborg M, Weijenberg MP, Roemen GM, de Bruine AP, van den Brandt PA, Lentjes MH, et al. APC mutations in sporadic colorectal carcinomas from The Netherlands Cohort Study. Carcinogenesis. 2004; 25(7):1219-1226. Epub 2004/02/21. [PubMed: 14976131] 


\section{Highlights}

1. Role of sphingolipids in colon cancer.

2. Endogenous and dietary effect of sphingolipids in colon cancer, and

3. Interaction of sphingolipids with $\mathrm{WNT} / \beta$-catenin pathway in colon. 


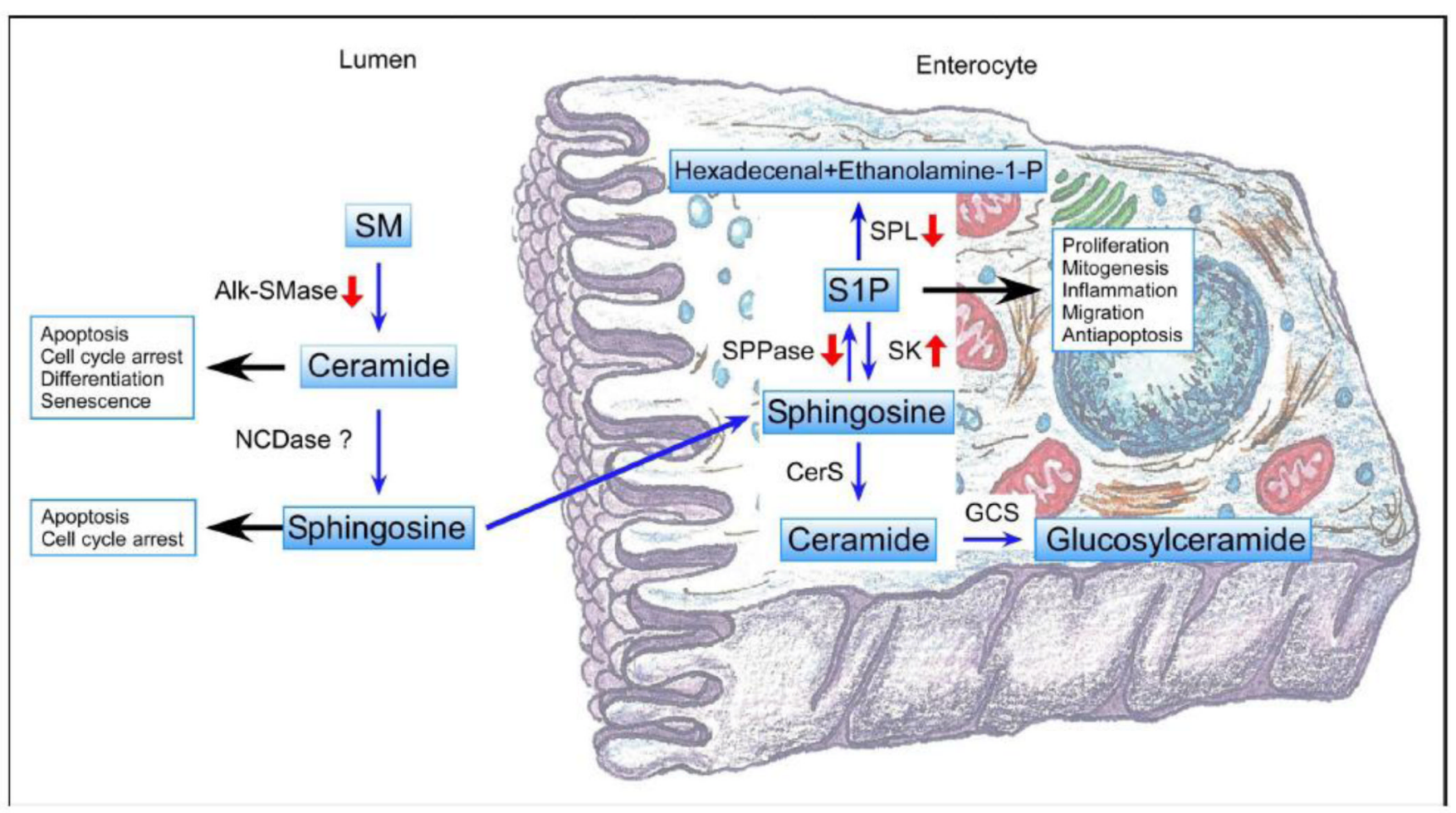

Figure 1.

Summary of the changes in sphingolipid metabolic enzyme described in colon cancer, along with an overview of the major roles in cell homeostasis. Figure based on figure 9 in Kono et. al. [65], with permission. SM: Sphingomyelin; alk-SMase: alkaline-Sphingomyelinase; nCDase: neutral Ceramidase; SPL: Sphingosine-1-P Lyase; S1P: Sphingosine-1-Phosphate; SPPase: Sphingosine-1-P Phosphatase; SK: Sphingosine Kinase; CerS: Ceramide Synthase and GCS: Glucosylceramide Synthase. 


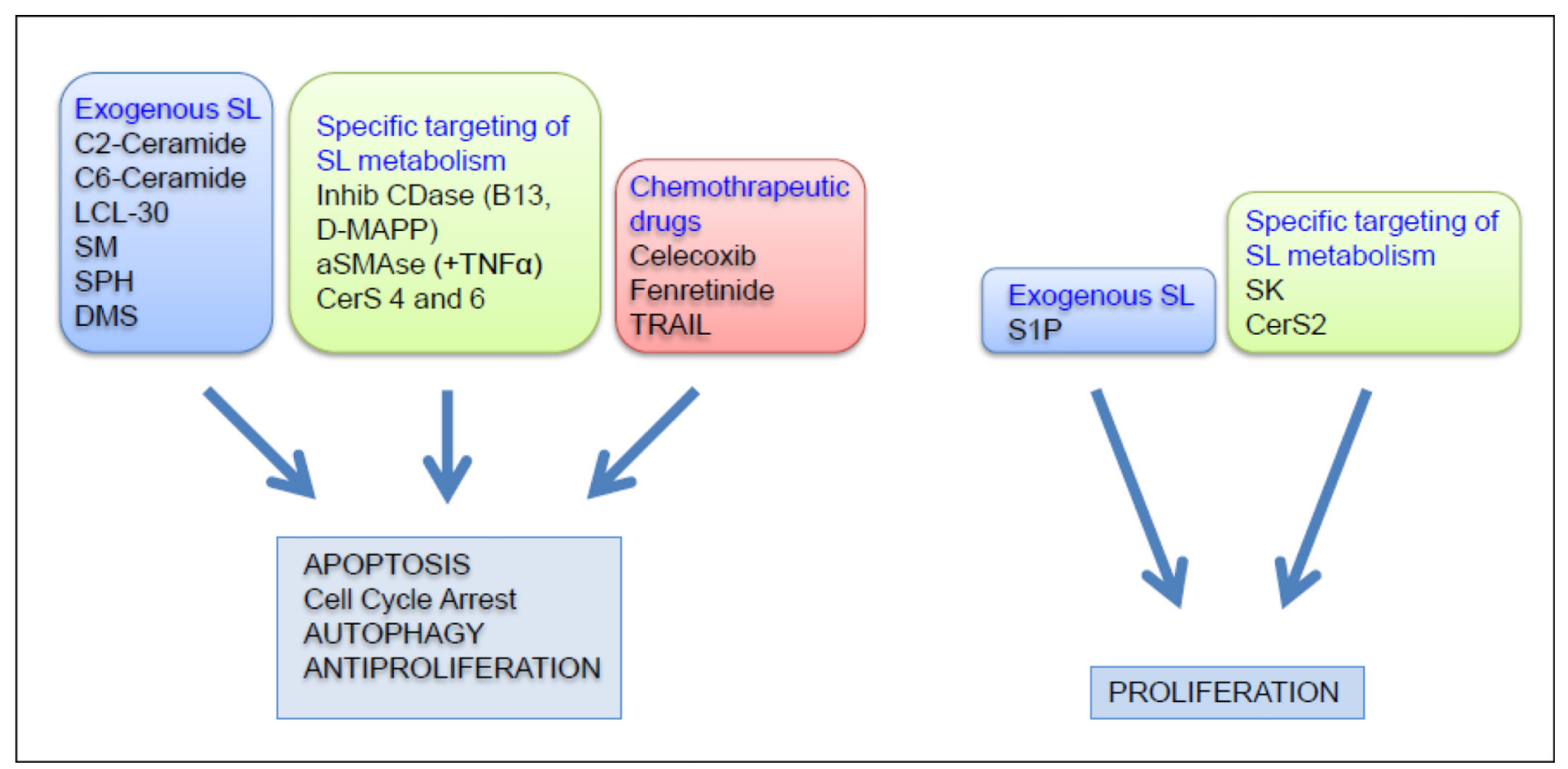

Figure 2.

Summary of the effects of sphingolipids in colon cancer cells. LCL-30: $\omega$-pyridinium bromide D-erythro-C16-ceramide; SM: Sphingomyelin; SPH: Sphingosine; DMS: N,Ndimethylsphingosine; CDase: Ceramidase; aSMase: acid Sphingomyelinase; TNF-a: Tumor Necrosis Factor alfa; CerS: Ceramide Synthase; TRAIL: TNF-Related Apoptosis-Inducing Ligand; S1P: Sphingosine 1 Phosphate; SK: Sphingosine Kinase. 